\title{
Patients undergoing elective coronary artery bypass grafting exhibit poor pre-operative intakes of fruit, vegetables, dietary fibre, fish and vitamin D
}

\author{
B. Ruiz-Núñez ${ }^{1 *}$, G. H. A. M. van den $\operatorname{Hurk}^{1}$, J. H. M. de $\operatorname{Vries}^{2}$, M. A. Mariani ${ }^{3}$, M. J. L. de Jongste ${ }^{3}$, \\ D. A. J. Dijck-Brouwer ${ }^{1}$ and F. A. J. Muskiet ${ }^{1}$ \\ ${ }^{1}$ Laboratory Medicine, University Medical Centre Groningen (UMCG), Building 33, 3rd floor, Room Y3.181, \\ Internal Zip Code EA61, Hanzeplein 1, PO Box 30.001, 9700RB Groningen, The Netherlands \\ ${ }^{2}$ Division of Human Nutrition, Wageningen University, Wageningen, The Netherlands \\ ${ }^{3}$ Thorax Centre, University Medical Centre Groningen (UMCG), Groningen, The Netherlands
}

(Submitted 19 May 2014 - Final revision received 6 November 2014 - Accepted 21 January 2015 - First published online 1 April 2015)

\section{Abstract}

CHD may ensue from chronic systemic low-grade inflammation. Diet is a modifiable risk factor for both, and its optimisation may reduce post-operative mortality, atrial fibrillation and cognitive decline. In the present study, we investigated the usual dietary intakes of patients undergoing elective coronary artery bypass grafting (CABG), emphasising on food groups and nutrients with putative roles in the inflammatory/anti-inflammatory balance. From November 2012 to April 2013, we approached ninety-three consecutive patients (80\% men) undergoing elective CABG. Of these, fifty-five were finally included ( $84 \%$ men, median age 69 years; range $46-84$ years). The median BMI was 27 (range $18-36$ ) $\mathrm{kg} / \mathrm{m}^{2}$. The dietary intake items were fruits (median $181 \mathrm{~g} / \mathrm{d}$; range $0-433 \mathrm{~g} / \mathrm{d}$ ), vegetables (median $115 \mathrm{~g} / \mathrm{d}$; range $0-303 \mathrm{~g} / \mathrm{d}$ ), dietary fibre (median $22 \mathrm{~g} / \mathrm{d}$; range $9-45 \mathrm{~g} / \mathrm{d}$ ), EPA+DHA (median $0.14 \mathrm{~g} / \mathrm{d}$; range $0.01-1.06 \mathrm{~g} / \mathrm{d}$ ), vitamin D (median $4.9 \mu \mathrm{g} / \mathrm{d}$; range $1.9-11.2 \mu \mathrm{g} / \mathrm{d}$ ), saturated fat (median $13.1 \%$ of energy (E\%); range 9-23 $\mathrm{E} \%$ ) and linoleic acid (LA; median $6.3 \mathrm{E} \%$; range $1.9-11.3 \mathrm{E} \%$ ). The percentages of patients with dietary intakes below recommendations were $62 \%$ (fruits; recommendation $200 \mathrm{~g} / \mathrm{d}$ ), 87\% (vegetables; recommendation 150-200 g/d), 73\% (dietary fibre; recommendation 30-45 g/d), 91\% (EPA+DHA; recommendation $0.45 \mathrm{~g} / \mathrm{d}$ ), $98 \%$ (vitamin $\mathrm{D}$; recommendation $10-20 \mu \mathrm{g} / \mathrm{d}$ ) and $13 \%$ (LA; recommendation 5-10 $\mathrm{E} \%$ ). The percentages of patients with dietary intakes above recommendations were $95 \%$ (saturated fat; recommendation $<10 \mathrm{E} \%$ ) and $7 \%$ (LA). The dietary intakes of patients proved comparable with the average nutritional intake of the age- and sex-matched healthy Dutch population. These unbalanced pre-operative diets may put them at risk of unfavourable surgical outcomes, since they promote a pro-inflammatory state. We conclude that there is an urgent need for intervention trials aiming at rapid improvement of their diets to reduce peri-operative risks.

Key words: Coronary artery bypass grafting surgery: Coronary artery disease: Diets: Low-grade inflammation

Atherosclerosis is a major cause of CHD, and its pathophysiological cascade is increasingly recognised to ensue from lifestyle-induced chronic systemic low-grade inflammation ${ }^{(1)}$. The modifiable risk factors for CHD are diet, smoking, hypertension, diabetes and lipid disorders, among others ${ }^{(2)}$. Coronary artery bypass grafting (CABG) is the standard revascularisation treatment for patients with severe atherosclerotic heart disease, such as left main and three-vessel $\mathrm{CHD}^{(3)}$ CABG is a major event that unavoidably induces an inflammatory response, mostly on top of an already existing state of systemic low-grade inflammation. The relatively old age of patients undergoing CABG, the often widespread atherosclerotic disease and the presence of CHD risk factors confer additional risks for vascular sequels ${ }^{(4)}$, frequently coinciding with (most often transient) paucity in brain function, the so-called post-operative cognitive dysfunction ${ }^{(5)}$.

An inflammatory reaction is essential for survival from various events. It is the reflection of an activated immune system aiming to protect us from traumas, invading pathogens or a response to sterile infection ${ }^{(6)}$. The systemic inflammatory

Abbreviations: AHA, American Heart Association; CABG, coronary artery bypass grafting; CARS, counter anti-inflammatory response syndrome; CHO, carbohydrates; E\%, percentage of energy; GL, glycaemic load; Nrf2, nuclear factor erythroid-2 related factor; SIRS, systemic inflammatory response syndrome.

*Corresponding author: B. Ruiz-Núñez, fax +31 50361 2290, email b.ruiz-nunez@umcg.nl 
response syndrome (SIRS) has become a widely accepted concept to explain the pathophysiology of systemic inflammation from multiple aetiologies, i.e. trauma, surgery and infections ${ }^{(7)}$. However, uncontrolled and secondary reactions resulting from an activated immune system harbour the capacity to kill us; therefore, any inflammatory reaction that has started should subsequently be ended, in order to limit the unavoidably associated collateral damage ${ }^{(8)}$. The antiinflammatory responses compensating for SIRS have been named the counter anti-inflammatory response syndrome $(\mathrm{CARS})^{(9)}$, characterised by a weakened host defence and augmented susceptibility to secondary infections. Consequently, restoration of an injured host to homeostasis requires the simultaneous involvement of both SIRS and CARS, while any disruption of their balance towards the extremes may result in, for example, immune suppression, cardiovascular collapse and organ failure ${ }^{(9)}$. In line with this view, it is plausible that, in some susceptible patients, CABG surgery acts as the catalyst for complications that are not present pre-operatively; while in others, it constitutes a burden on top of a system already showing a decline ${ }^{(10)}$.

There are numerous false inflammatory triggers in our current, typically Western, lifestyle that may collectively lead to a state of chronic systemic low-grade inflammation, eventually leading to atherosclerosis and CHD. These false triggers hijack an evolutionary conserved interaction between our immune system and metabolism ${ }^{(11)}$. Among the proinflammatory factors in our current diet are consumption of trans-fatty acids, a high $n-6: n-3$ fatty acid ratio, a low intake of $n-3$ fatty acids from fish, a low vitamin D status, a low-fibre diet and low intakes of fruit and vegetables ${ }^{(12)}$. Nevertheless, less than $25 \%$ of the Dutch population follows the recommendations regarding the consumption of fruit, vegetables and dietary fibre; in 1998, the average fish consumption in The Netherlands amounted to hardly three times per month ${ }^{(13)}$. Eating fish once a week has been associated with a $15 \%$ lower risk of CHD death compared with consumption of less than once per month ${ }^{(14)}$.

The aim of the present study was to assess the dietary intakes of patients undergoing elective CABG, emphasising on food groups and nutrients known to play important roles in the inflammatory/anti-inflammatory balance. Habitual dietary intakes were estimated by means of a FFQ. We anticipate that the results will enable us to identify (subgroups of) patients with high risk of (post)-surgical complications with the ultimate aim to develop strategies for minimising postCABG complications and their ensuing comorbidities by targeting diet as a relatively easy-to-modify risk factor.

\section{Experimental methods \\ Study design and study group}

Patients were recruited from two cardiothoracic nursing units of the Universal Medical Center Groningen, The Netherlands, Between November 2012 and April 2013, all consecutive patients admitted for elective CABG surgery were approached for voluntary participation (ninety-three patients: seventy-four males and nineteen females). Of these, sixteen (17\%) declined participation due to the extent of the FFQ ( $n$ 8, 50\%), not being able to read ( $n$ 4, 25\%) or understand and/or capable to read Dutch ( $n 1,6 \%)$, confusion $(n 1,6 \%)$ or being too occupied with diagnostic examinations ( $n$ 2, 12\%). Of the remaining seventy-seven patients who agreed to fill out the FFQ, fifty-five were ultimately included (71\%; forty-six males and nine females). The reasons for dropping-out from the study were incomplete questionnaires ( $n$ 10, 13\%), CABG surgery not being performed ( $n$ 5, 6\%), incorrectly filled out questionnaires ( $n 3,4 \%$ ) and others (one patient not scheduled for CABG (1\%), two patients not returning the FFQ (2\%) and one death (1\%)).

\section{FFQ}

For the estimation of nutritional intakes, we used a FFQ from the Division of Human Nutrition at the Wageningen University, The Netherlands. This questionnaire is based on the FFQ developed and validated by Feunekes et $a{ }^{(15)}$ for fats and cholesterol, and was updated with the Dutch National Food Consumption Survey 2007-10 $0^{(16)}$ and the Dutch National Food Composition Database 2010 version $2.0^{(17)}$. The composed FFQ was evaluated using the mean of three $24 \mathrm{~h}$ recalls as the reference method ${ }^{(18)}$, where fair associations were encountered for intakes of vitamin D, dietary fibre, vegetables and fruit ${ }^{(18)}$. For the same FFQ, very strong associations were found for energy intake ${ }^{(19)}$. Patients were asked to report on their dietary habits during the previous 4 weeks. In case they had changed their diets because of sickness or had followed a special hospital diet within this period, they were requested to provide information on what they ate during the last 4 weeks according to their regular dietary habits. The completeness of the information was checked by a trained researcher using a specific checklist. Correctly filled out FFQ were digitised and processed using the Dutch FFQ-TOOL ${ }^{\mathrm{TM}}$, which is a computer system that generates and processes FFQ tailored for specific research questions and/or populations ${ }^{(20)}$. In the Dutch FFQ-TOOL $^{\mathrm{TM}}$, the nutrient composition of each food item is derived from the weighted mean composition of the single foods of which the food item consists ${ }^{(20)}$, as weighted by the reported amounts in the Dutch Food Composition Database $2010^{(17)}$.

Data on age of the subjects were obtained by interviews in the Dutch language. Weight and height were self-reported or measured on the spot. Participants were asked whether they had gained or lost weight in the past year, and whether they consumed vitamin or mineral supplements (i.e. vitamin D, (multi)vitamins and/or fish oil).

\section{Data analysis}

Outcome data of the FFQ were compared with the Dutch $^{(16,21,22)}$ and American ${ }^{(23,24)}$ dietary recommendations. Because of their physical condition, we considered the patients as sedentary, and compared their energy intakes with those recommended for the equivalent physical activity 
level for each group. We visually compared the outcomes with the dietary intakes of representative age- and sex-matched healthy subjects in the Dutch general population. For this comparison, we calculated the 5th, 50th and 95th percentiles for the outcomes of the male and female patients, and related them with the corresponding 5th, 50th and 95th percentiles of the healthy population, as established in the Dutch Food Consumption Survey 2007-10 ${ }^{(16)}$.

\section{Healthy eating score and adherence to recommendations}

A 'healthy eating score' was calculated from four items of main interest, i.e. the intakes of fruits, vegetables, fibre and EPA+DHA. For each of these items, patients were categorised according to their quintiles of intake in order to obtain a score from 1 (lowest quintile) up to 5 (highest quintile). The outcomes of the four items were summed, obtaining the healthy eating score, in which the minimum score was 4 , while twenty constituted the maximum score. We also investigated whether individual patients adhered to the recommendations for each of these four nutrients/food items. These numbers (0-4) were plotted in a frequency curve showing how often the sums of these four recommendations were fulfilled.

\section{Statistical analysis}

Percentiles and graphs for visual comparison and calculation of healthy eating score were performed with PASW version 18.0 (SPSS, Inc.)

\section{Results}

\section{Characteristics of the study population}

A total of fifty-five patients (forty-six males and nine females) with a median age of 69 (range 46-84) years were included. The median height was 176 (range $160-204) \mathrm{cm}$, the median weight was 83 (range 47-120) kg and the median BMI was 27 (range $18-36) \mathrm{kg} / \mathrm{m}^{2}$. Within the whole study group, eight patients reported as taking some form of supplement. Of these eight patients, three took a vitamin D supplement, three a vitamin $\mathrm{C}$ supplement, two a multivitamin supplement and one a supplement containing both $n-3$ and $n-6$ fatty acids. Dosages were not specified and, therefore, were not used in the calculations.

\section{Outcomes of FFQ compared with Dutch and US recommendations}

Table 1 shows the outcomes of FFQ and its comparison with the dietary recommendations for the $\operatorname{Dutch}^{(16,21,22)}$ and Americans ${ }^{(23,24)}$.

Energy intake. The median energy intake in the present study group was 9309 (range 4565-18548) kJ/d (2225 (range $1091-4433) \mathrm{kcal} / \mathrm{d}$ ). Of the fifty-five patients, twenty-one (38\%) reported energy intakes below the Dutch and American requirements for their age- and sex-specific groups (Table 1), while thirty-four (62\%) reported energy intakes above these requirements.

Fruit, vegetables and dietary fibre intakes. The median fruit intake of the present study group was 181 (range $0-433) \mathrm{g} / \mathrm{d}$ (Table 1 ). The recommended fruit intake is $200 \mathrm{~g} / \mathrm{d}$ in the Netherlands and $200-250 \mathrm{~g} / \mathrm{d}$ (4-5 servings/ d) in the USA. In the present study, $62 \%$ of patients reported a fruit intake below, and only 38 and $22 \%$ reported fruit intakes equal to or above the respective Dutch and American recommendations.

The median vegetable intake of the present study group was 115 (range $0-303$ ) g/d. The recommended vegetable intake is $200 \mathrm{~g} / \mathrm{d}$ in The Netherlands and $200-300 \mathrm{~g} / \mathrm{d}(4-5$ servings/d) in the USA. Pursuant to these quantities, $87 \%$ of the patients failed to fulfil the Dutch or the American recommendations, while only 13 and $2 \%$, respectively, did fulfil them. Dietary fibre consumption was below recommendations $(25 \mathrm{~g} / \mathrm{d}$ in The Netherlands and $22-28 \mathrm{~g} / \mathrm{d}$ in the USA) in 73 and $78 \%$ of patients (median $22 \mathrm{~g} / \mathrm{d}$; range $9-45 \mathrm{~g} / \mathrm{d}$ ), and 27 and $22 \%$ of them reported a dietary fibre consumption equal to or above these recommendations, respectively.

Carbohydrate, protein and fat intakes. The median energy intake from carbohydrates $(\mathrm{CHO})$ in the present study group was $44 \%$ of energy (E\%; range $24-58 \mathrm{E} \%$ ) (Table 1). The Dutch and American recommendations are 40-70 and 45$65 \mathrm{E} \%$, respectively. Consequently, $27 \%$ of patients reported a $\mathrm{CHO}$ intake below the Dutch recommendations and 58\% below the US recommendations, while none of the patients reported $\mathrm{CHO}$ intakes equal to or beyond these recommendations. The median protein intake was below the recommendations in only $2 \%$ of the study population $(15 \mathrm{E} \%$; range 9-21 E\%; recommendations $10-25 \mathrm{E} \%$ in The Netherlands and $10-35 \mathrm{E} \%$ in the USA). The median fat consumption was $35 \mathrm{E} \%$ (range $26-51 \mathrm{E} \%$ ), which is within the range of both the Dutch (20-40 E\%) and the American (20-35 E\%) recommendations. None of the patients reported a fat intake below these recommendations; however, 22 and $49 \%$ of the study group reported fat intakes equal to or above the Dutch and American recommendations, respectively.

Saturated fat, trans-fat, linoleic acid, EPA and DHA intakes. The median consumption of SFA $(13 \mathrm{E} \%$; range 9-23E\%; Table 1) was above the upper limit of the Dutch and American recommendations (both $10 \mathrm{E} \%$ ). None of the patients reported a SFA intake below the American Heart Association (AHA) recommendation of $<7 \mathrm{E} \%{ }^{(24)}$.

Trans-fat consumption (median $0.6 \mathrm{E} \%$; range $0.3-1.0 \mathrm{E} \%$ ) was below the upper limit of $1 \mathrm{E} \%$ recommended in The Netherlands and by the $\mathrm{AHA}^{(24)}$ in $98 \%$ of patients (all except for one patient, $2 \%$ ).

The Dutch linoleic acid recommendation of at least $2 \mathrm{E} \%$ to prevent essential fatty acid deficiency ${ }^{(21)}$ was fulfilled by $98 \%$ of the study population (median $6.3 \mathrm{E} \%$; range $1.9-11.3 \mathrm{E} \%$ ). Linoleic acid consumption was within the American recommendations (acceptable macronutrient distribution range $5-10 \mathrm{E} \%$ ) in $80 \%$ of the present study group, while $13 \%$ reported intakes below and $7 \%$ reported intakes equal to or above the recommended range. 
Table 1. Outcomes of FFQ for fifty-five patients awaiting coronary artery bypass grafting compared with the dietary recommendations for the Dutch and Americans (Median values and ranges; number of patients and percentages)

\begin{tabular}{|c|c|c|c|c|c|c|c|c|c|c|c|c|}
\hline & & & \multicolumn{5}{|c|}{ Dutch recommendations } & \multicolumn{5}{|c|}{ US recommendations } \\
\hline & \multicolumn{2}{|r|}{ Patients } & \multirow[b]{2}{*}{ Guideline } & \multicolumn{2}{|c|}{ Below } & \multicolumn{2}{|c|}{ Above } & \multirow[b]{2}{*}{ Guideline } & \multicolumn{2}{|c|}{ Below } & \multicolumn{2}{|c|}{ Above } \\
\hline & Median & Range & & $\%$ & $n$ & $\%$ & $n$ & & $\%$ & $n$ & $\%$ & $n$ \\
\hline \multirow[t]{6}{*}{ Energy (kJ/d) } & $9309(2225 \mathrm{kcal} / \mathrm{d})$ & $4565-18548(1091-4433 \mathrm{kcal} / \mathrm{d})$ & $\begin{array}{c}\text { Female } \leq 50 \text { years: } \\
2317 \mathrm{kcal} / \mathrm{d}^{*}\end{array}$ & 0 & 0 & 100 & 1 & $\begin{array}{c}\text { Female } \leq 50 \text { years: } \\
1800 \mathrm{kcal} / \mathrm{d} \dagger\end{array}$ & 0 & 0 & 100 & 1 \\
\hline & & & $\begin{array}{c}\text { Female } 51-70 \text { years: } \\
2150 \mathrm{kcal} / \mathrm{d}^{\star}\end{array}$ & 75 & 3 & 25 & 1 & $\begin{array}{c}\text { Female }>51 \text { years: } \\
1600 \mathrm{kcal} / \mathrm{d} \dagger\end{array}$ & 63 & 5 & 37 & 3 \\
\hline & & & $\begin{array}{c}\text { Female }>70 \text { years: } \\
1863 \mathrm{kcal} / \mathrm{d}^{*}\end{array}$ & 25 & 2 & 25 & 2 & & & & & \\
\hline & & & $\begin{array}{c}\text { Male } \leq 50 \text { years: } \\
2914 \mathrm{kcal} / \mathrm{d}^{*}\end{array}$ & 0 & 0 & 100 & 1 & & & & & \\
\hline & & & $\begin{array}{l}\text { Male } 51-70 \text { years: } \\
2627 \mathrm{kcal} / \mathrm{d}^{*}\end{array}$ & 30 & 8 & 70 & 19 & $\begin{array}{c}\text { Male } \leq 60 \text { years: } \\
2200 \mathrm{kcal} / \mathrm{d} \dagger\end{array}$ & 13 & 1 & 87 & 7 \\
\hline & & & $\begin{array}{l}\text { Male }>70 \text { years: } \\
2221 \mathrm{kcal} / \mathrm{d}^{*}\end{array}$ & 44 & 8 & 56 & 10 & $\begin{array}{c}\text { Male }>60 \text { years: } \\
2000 \mathrm{kcal} / \mathrm{d} \dagger\end{array}$ & 39 & 15 & 61 & 23 \\
\hline Fruit $(g / d)$ & 181 & $0-433$ & $200 \ddagger$ & 62 & 34 & 38 & 21 & $4-5$ servings $(200-250 \mathrm{~g}) \dagger$ & 62 & 34 & 22 & 12 \\
\hline Vegetables $(\mathrm{g} / \mathrm{d})$ & 115 & $0-303$ & $200 \ddagger$ & 87 & 48 & 13 & 7 & $4-5$ servings $(200-300 \mathrm{~g}) \dagger$ & 87 & 48 & 2 & 1 \\
\hline Dietary fibre (g/d) & 22 & $9-45$ & $25 \ddagger$ & 73 & 40 & 27 & 15 & $\begin{array}{l}\text { Female: } 22 \dagger \\
\text { Male: } 28 \dagger\end{array}$ & $\begin{array}{l}78 \\
78\end{array}$ & $\begin{array}{r}7 \\
36\end{array}$ & $\begin{array}{l}22 \\
22\end{array}$ & 2 \\
\hline Carbohydrates (E\%) & 44 & $24-58$ & $40-70 \S$ & 27 & 15 & 0 & 0 & $45-65 \|$ & 58 & 32 & 0 & 0 \\
\hline Protein (E\%) & 15 & $9-21$ & $10-25^{*}$ & 2 & 1 & 0 & 0 & $10-35 \|$ & 2 & 1 & 0 & 0 \\
\hline Fat $(E \%)$ & 35 & $26-51$ & $20-40^{\star}$ & 0 & 0 & 22 & 12 & $20-35 \|$ & 0 & 0 & 49 & 27 \\
\hline Saturated fat (E\%) & 13 & $9-23$ & Upper limit: $10 \ddagger$ & 5 & 3 & 95 & 52 & $\begin{array}{l}<10 \dagger \\
<7 \|\end{array}$ & $\begin{array}{l}5 \\
0\end{array}$ & $\begin{array}{l}3 \\
0\end{array}$ & $\begin{array}{r}95 \\
100\end{array}$ & $\begin{array}{l}52 \\
55\end{array}$ \\
\hline Trans-fat (E\%) & 0.6 & $0.3-1.0$ & Upper limit: $1 \ddagger$ & 98 & 54 & 2 & 1 & $<19$ & 98 & 54 & 2 & 1 \\
\hline LA (E\%) & $6 \cdot 3$ & $1 \cdot 9-11 \cdot 3^{\star \star}$ & At least $2 \S$ & 2 & 1 & 98 & 54 & $5-10+\dagger$ & 13 & 7 & 7 & 4 \\
\hline$E P A+D H A(g / d)$ & 0.14 & $0.01-1.06^{\star \star}$ & $0.45 \S$ & 91 & 50 & 9 & 5 & $1 \|$ & 98 & 54 & 2 & 1 \\
\hline \multirow[t]{2}{*}{ Vitamin $D(\mu \mathrm{g} / \mathrm{d})$} & 4.9 & $1 \cdot 9-11 \cdot 2^{* \star}$ & $<70$ years: $10 \S$ & 97 & 28 & 3 & 1 & $<70$ years: $15 \|$ & 100 & 29 & 0 & 0 \\
\hline & & & $\geq 70$ years: $20 \S$ & 100 & 26 & 0 & 0 & $\geq 70$ years: $20 \|$ & 100 & 26 & 0 & 0 \\
\hline
\end{tabular}

E\%, percentage of energy; LA, linoleic acid.

†Data from the US Department of Agriculture and the US Department of Health and Human Services ${ }^{(23)}$

$\S$ Data from the Health Council of The Netherlands ${ }^{(21)}$.

\| Data from Kris-Etherton et al. ${ }^{(25)}$.

Data from Eckel et al. ${ }^{(86)}$

take (dosage not known).

†† Data from the Institute of Medicine (US), Panel on Macronutrients and Standing Committee on the Scientific Evaluation of Dietary Reference Intakes ${ }^{(87)}$. 
The consumption of EPA+DHA (median $0.14 \mathrm{~g} / \mathrm{d}$; range $0.01-1.06 \mathrm{~g} / \mathrm{d}$ ) was below the Dutch recommendations of $0.45 \mathrm{~g} / \mathrm{d}$ in $91 \%$ of the patients. Except for one patient ( $2 \%$, who was not the patient taking $n-3$ and $n-6$ fatty acid supplements), none of them complied with the AHA recommendation of $1 \mathrm{~g} / \mathrm{d}$ for patients with documented $\mathrm{CHD}^{(25)}$.

Vitamin $D$ intake. The RDA for vitamin $\mathrm{D}$ in The Netherlands is $10 \mu \mathrm{g} / \mathrm{d}(0-69$ years) and $20 \mu \mathrm{g} / \mathrm{d}$ ( $\geq 70$ years). Irrespective of sunlight exposure, all 0 - to 4 -year-old children, pregnant women and 50- to 70-year-old women are advised to take a supplement of $10 \mu \mathrm{g} / \mathrm{d}$, while all subjects $\geq 70$ years are recommended to take a supplement of $20 \mu \mathrm{g} / \mathrm{d}$. Females (age 4-50 years) and males (age 4-70 years) are recommended to take a supplement of $10 \mu \mathrm{g} / \mathrm{d}$ if they are insufficiently exposed to vitamin D-producing sunlight. The latter is applicable for subjects living in The Netherlands from November until February ${ }^{(26)}$ and greatly overlaps the present study period. This implies that all patients $<70$ years should be taking $10 \mu \mathrm{g}$ vitamin $\mathrm{D} / \mathrm{d}$, while all $\geq 70$-year-old patients should be taking $20 \mu \mathrm{g} / \mathrm{d}$. Except for one patient $(3 \%$ of the study population below 70 years, $2 \%$ of the total study population), none of them reported a vitamin D intake from food (median $4.9 \mu \mathrm{g} / \mathrm{d}$; range 1.9$11.2 \mu \mathrm{g} / \mathrm{d}$ ) that reached the daily needs, while none of them complied with the American recommendations (for unexposed subjects $15 \mu \mathrm{g} / \mathrm{d}$ for $1-69$ years, and $20 \mu \mathrm{g} / \mathrm{d}$ for $\geq 70$ years). Except for the three patients ( $5 \%$, dosage unknown), none of them reported the use of a vitamin D supplement.

Healthy eating score and percentage fulfilment of recommendations. The results for the calculation of the healthy eating score are shown in Fig. 1(a). None of the patients reached the minimum and maximum scores of 4 and 20 , respectively. The distribution showed an arbitrary subgroup of eight patients (15\%) with scores of 8 and below. The distribution of the number of fulfilled dietary recommendations (Fig. 1(b)) showed a steep decrease from $38 \%$ of patients ( $n$ 21), who did not fulfil any of the four recommendations and $38 \%$ fulfilling only one of the recommendations, to zero patients fulfilling all the four recommendations.

\section{Outcomes of FFQ compared with the healthy Dutch population}

Fig. 2 shows the dietary intakes of CABG patients compared with those of their age- and sex-matched healthy counterparts in The Netherlands. Visual inspection revealed that the median fruit consumptions by male and female patients appeared somewhat higher than the corresponding intakes by their age- and sex-matched healthy counterparts (Fig. 2(a)). For the female patients, the median fruit consumption was just above the Dutch and American recommendation of $200 \mathrm{~g} / \mathrm{d}$; however, this was not the case for healthy females and the two male groups, who presented lower intakes. Of the healthy Dutch men, at least $75 \%$ did not adhere to the recommended fruit intake.

For vegetables (Fig. 2(b)), the median consumption by female patients was similar to that of their age-matched healthy Dutch counterparts, whereas in male patients, the median intake appeared lower. In all groups, approximately
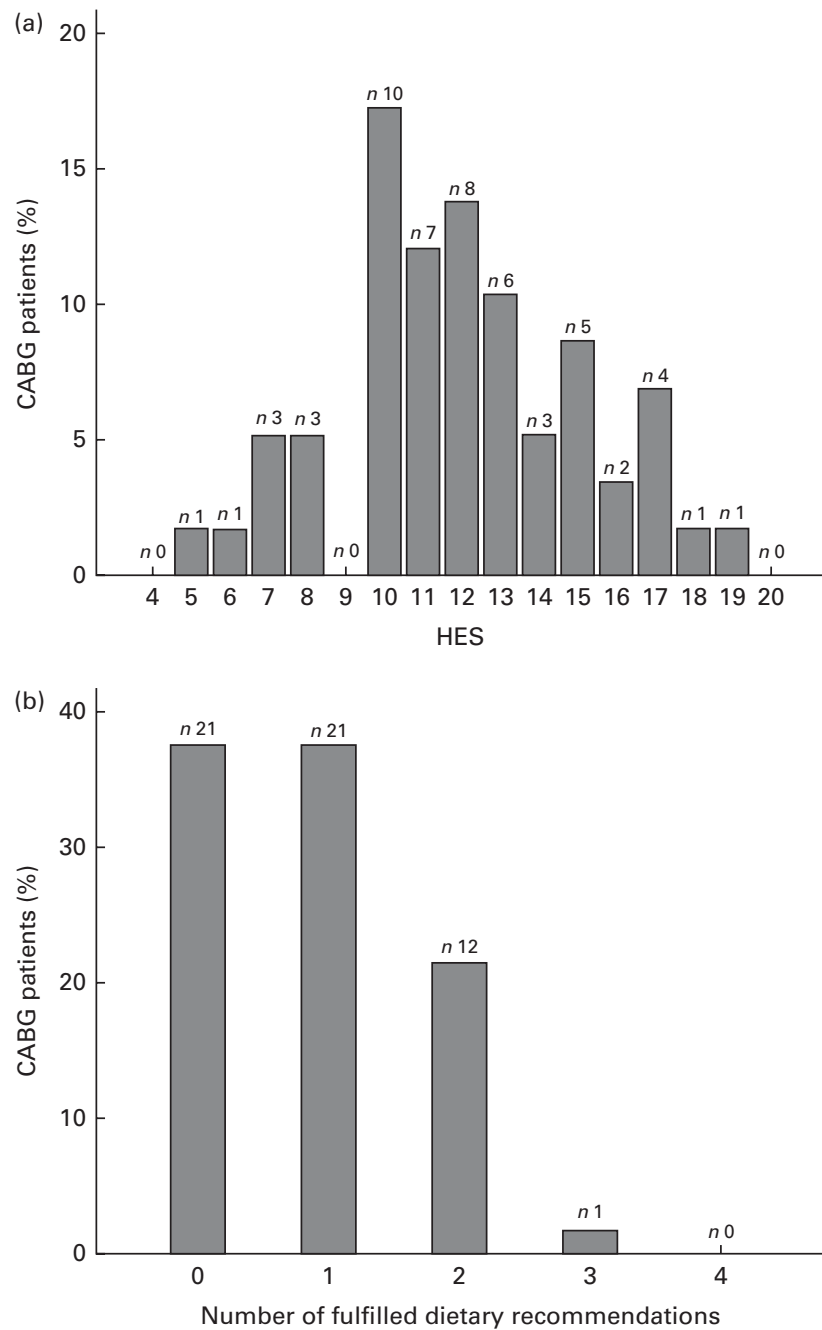

Fig. 1. 'Healthy eating score' (HES) and degree of dietary recommendation fulfilment for fifty-five patients awaiting coronary artery bypass grafting (CABG). (a) The percentages of patients with indicated HES ranging from 4 to 20 . HES was obtained by dividing four important dietary variables into quintiles. These were the intakes of vegetables, fruit, dietary fibre and $\mathrm{EPA}+\mathrm{DHA}$. For each variable, patients were given a score, from 1 (lowest quintile) to 5 (highest). For each patient, the scores were summed to obtain the HES (minimum 4 and maximum 20). There seems to be an arbitrary subgroup with scores of 8 and below. (b) The distribution of the number of recommendations that the various patients fulfilled. It was found that $76 \%$ ( $n$ 42) of the patients adhered to none of the four recommendations or just one of them. None of the patients adhered to all the four recommendations.

$75 \%$ showed vegetable intakes that did not meet the recommendations.

The median dietary fibre consumption by female patients was similar to the median consumption by their healthy Dutch counterparts (Fig. 2(c)). Both groups exhibited median fibre intakes below the Dutch and American recommendations. The median fibre intake by male patients was somewhat higher than their healthy counterparts, and was similar to the Dutch recommendation.

The median EPA+DHA consumptions of both the female patient and healthy groups were similar; however, the consumption of EPA+DHA by male patients seemed somewhat higher than that of their age- and sex-matched healthy 

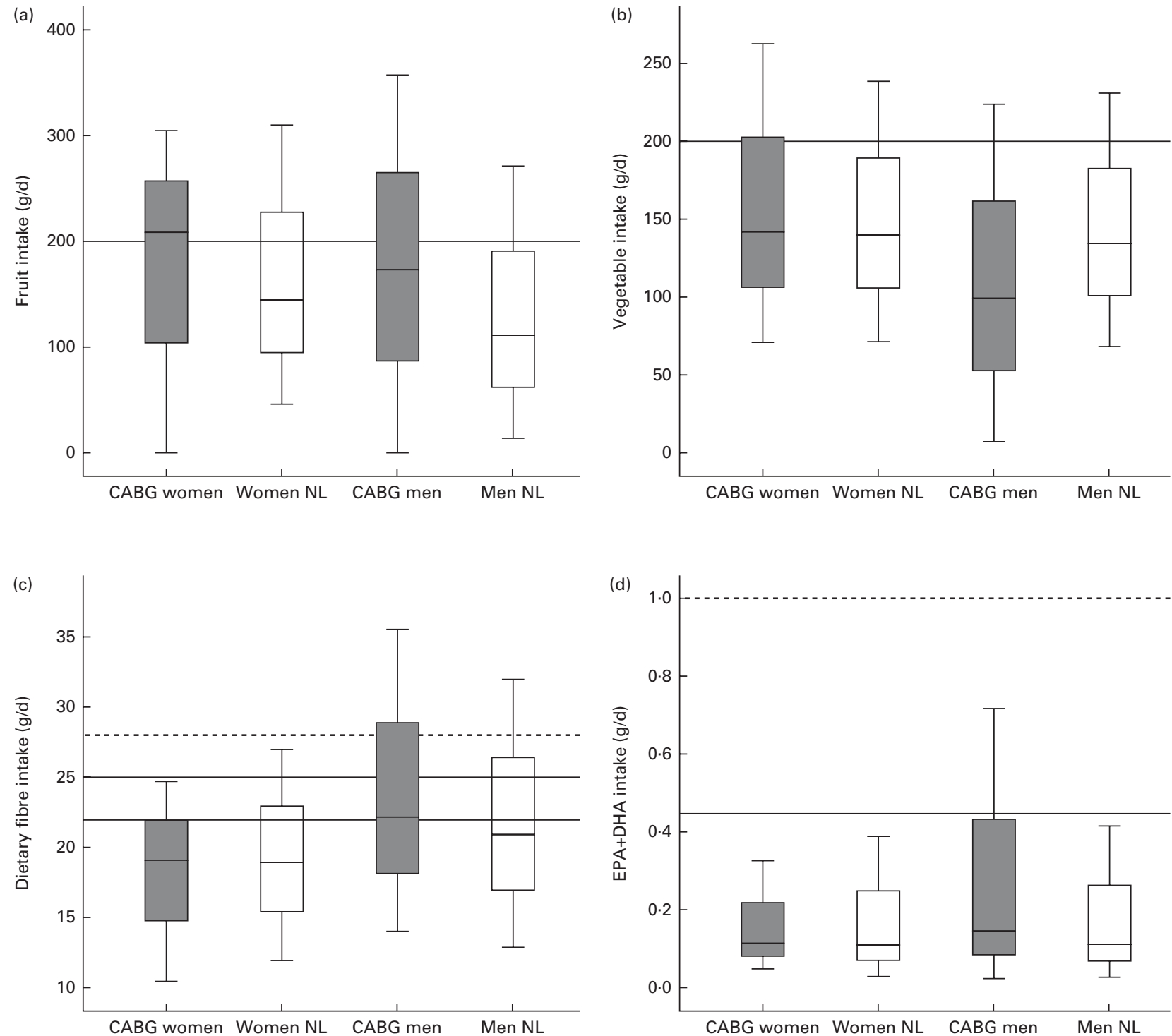

Fig. 2. Outcomes of $F F Q$ for fifty-five patients awaiting coronary artery bypass grafting (CABG) compared with data from healthy counterparts participating in the Dutch Food Consumption Survey 2007-10. Data are presented as boxplots for the estimated intakes of fruits (a), vegetables (b), fibre (c) and EPA+DHA (d). Full lines represent the Dutch and the US recommendations for fruit and vegetables ( $a$ and $b$ ), the US recommendations for fibre intake by females (c), and the Dutch recommendations for EPA+DHA intakes (d). Dotted lines represent the US recommendation for fibre intake in males (c) and the American Heart Association recommendation for patients with established CHD (d). Bold line represents the Dutch recommendation for fibre intake (c). CABG men, male patients awaiting CABG; CABG women, female patients awaiting CABG; NL, The Netherlands; Men NL, age-matched males from the Dutch Food Consumption Survey 2007-10; Women NL, age-matched females from the Dutch Food Consumption Survey 2007-10.

counterparts (Fig. 2(d)). In all the four groups, at least $75 \%$ of the intakes did not reach the Dutch recommendations, and all $\mathrm{EPA}+\mathrm{DHA}$ intakes were far below the AHA recommendation for subjects with documented CVD ${ }^{(25)}$.

\section{Discussion}

We estimated the dietary intakes of patients undergoing elective CABG using a FFQ. To the best of our knowledge, such data have not been reported before, with the exception of energy intakes ${ }^{(27)}$. A recent study in Iranian CHD patients ${ }^{(28)}$ has reported a low fish consumption within this group, together with a fruit and vegetable consumption within the 'safe' recommended range. Our main focus was set on food groups and nutrients with putative key roles in the inflammatory/anti-inflammatory balance. The present study population was relatively old ( 69 years; range $46-84$ years) and predominantly overweight/obese $\left(27 \mathrm{~kg} / \mathrm{m}^{2}\right.$; range $\left.18-36 \mathrm{~kg} / \mathrm{m}^{2}\right)$. The majority of patients did not reach the recommended dietary intakes of vegetables (87\%), fruits (62\%), fibre (73\%), EPA+DHA (91\%) and vitamin D (98\%), while 95\% of them did not adhere to the recommendation to take a vitamin D supplement. There were no appreciable differences between the above intakes by the present patient group and their healthy age- and sex-matched counterparts in the general Dutch population. 
The systemic low-grade inflammation is considered to play a central role in many, if not all, typically Western diseases ${ }^{(12)}$ It is even likely to be a causal factor in the pathophysiological cascade towards $\mathrm{CHD}^{(1)}$. Diets low in $n$-3 fatty acids, natural antioxidants, fibre, and vegetables and fruits have been associated with low-grade inflammation ${ }^{(29)}$, and the same applies for a low vitamin D status ${ }^{(30)}$. We will, therefore, discuss our findings in the context of low-grade inflammation, CHD and post-CABG cognitive dysfunction ${ }^{(5)}$, the latter being a major complication after surgery in the framework of brain inflammatory diseases.

\section{Long-chain n-3-PUFA}

The majority of patients (91\%) did not reach the recommended intakes of fish rich in EPA+DHA. Numerous studies have supported the important role of dietary fatty acids in low-grade inflammation. The metabolites of arachidonic acid, EPA and DHA are intimately involved in wound healing and other immune challenges ${ }^{(31)}$. The initial Gruppo Italiano per lo Studio della Sopravvivenza nell'Infarto Miocardico (GISSI)Prevenzione study ${ }^{(32)}$ and the Japan EPA Lipid Intervention Study ${ }^{(33)}$ supported the use of fish oil supplements in secondary prevention of CHD; however, a recent meta-analysis ${ }^{(34)}$ and a systematic review ${ }^{(35)}$ have yielded conflicting results, probably because fish oil may not add a preventive effect_ on top of the highly effective current drug treatment ${ }^{(36)}$. However, EPA and DHA also exhibit protective effects on cognitive decline and depression ${ }^{(37)}$, conditions that are increasingly recognised as inflammatory diseases ${ }^{(38,39)}$. In rats, brain function is sensitive to dietary $n$-3-PUFA intake, since $n$-3-PUFA deprivation during 15-18 weeks reduced brain DHA levels and induced functional brain changes, increasing aggression and depression scores ${ }^{(40)}$.

\section{SFA, linoleic acid and trans-fatty acids}

Almost the entire group (95\%) reported a SFA intake above the recommendations, 98\% reported a linoleic acid intake above the recommended intake of at least $2 \mathrm{E} \%$ and only $2 \%$ reported a trans-fatty acid intake above the recommendations. The widely accepted harmful effects of dietary SFA in CHD are increasingly questioned ${ }^{(41)}$, while in recent meta-analyses of randomised controlled trials, it has been concluded that partial replacement of dietary SFA for linoleic acid, the dominating dietary PUFA, insignificantly increases CHD risk ${ }^{(42)}$. Furthermore, SFA intake alone is not a predictor of CHD, whereas the intake of industrially produced transfatty acids is associated with CHD, independent of other dietary and CHD risk factors ${ }^{(43)}$. Despite the prominent contributions of dairy products and meat to SFA intake, neither of them have been consistently associated with CHD risk ${ }^{(44,45)}$.

There are many factors interacting with dietary SFA, and the outcome of these interactions may determine whether SFA will accumulate in the body, will be de novo synthesised and will eventually contribute to low-grade inflammation ${ }^{(4)}$. An important factor is a high $\mathrm{CHO}$ intake (further discussed), which promotes de novo lipogenesis, including de novo SFA synthesis, and, in addition, the sparing of dietary $\mathrm{SFA}^{(47)}$.

\section{Carbohydrates}

$\mathrm{CHO}$ intake was within the recommended intake in $73 \%$ of the present study population. High-CHO, low-fat diets and insulin resistance have been shown to augment de novo lipogenesis $^{(48)}$, and thereupon, in order to induce the synthesis of pro-inflammatory SFA, notably palmitate. CHD patients are likely to present low insulin sensitivity ${ }^{(49)}$, secondary to lifestyle-induced systemic low-grade inflammation ${ }^{(12)}$. This condition might be at the basis of the CHD aetiology, and become aggravated by the sedentary lifestyle that usually comes along with the progression of disabling CHD. Taken together, this implies that high- $\mathrm{CHO}$ (especially $\mathrm{CHO}$ with a high glycaemic load (GL)/glycaemic index) high-SFA diets are contraindicated in this patient group.

\section{Dietary fibre}

The majority of the present study group (73\%) reported a fibre intake below the dietary recommendations. The relationship between fibre and low-grade inflammation is complex. A high fibre diet may decrease the ratio between the Grampositive Firmicutes and the Gram-negative Bacteroidetes in the gut ${ }^{(50)}$. This shift coincides with the colonic fermentation of fibre by flora selection ${ }^{(51)}$, stimulates SCFA production ${ }^{(50)}$, may improve gut integrity ${ }^{(52)}$ and may, thereby, reduce chronic inflammation. In the same scenario, by virtue of their interchangeability at constant $\mathrm{CHO}$ intake, the often quoted anti-inflammatory capability of a high-fibre intake proved less consistent than for diets with low glycaemic indices or $\mathrm{GL}^{(53)}$. These data suggest that high dietary fibre might be a proxy for a low-glycaemic index/GL diet, and highlights the pro-inflammatory effect of a high glycaemic index/GL ${ }^{(12)}$.

\section{Vegetables and fruit}

Only 13 and $38 \%$ of the present study group reported a vegetable and fruit intake within the dietary recommendations, respectively. Diets low in vegetables and fruit have been associated with inflammation ${ }^{(12)}$ and have also been convincingly associated with hypertension, CHD and stroke ${ }^{(54)}$. Meta-analyses of prospective studies have indicated that less than $3 v \cdot 5+$ servings of vegetables and fruit per $\mathrm{d}$ correspond with a $17 \%$ CHD reduction ${ }^{(55)}$. A recent study has reported a robust inverse relationship of vegetable and fruit consumption with cancer, CHD and all-cause mortality, with benefits up to $7+$ portions per $\mathrm{d}^{(56)}$. Vegetables and fruit have the highest (micro)nutrient density scores of all major food groups ${ }^{(57)}$. They are not only rich in protein, fibre, vitamins and minerals, but also in antioxidants, which may collectively be responsible for their protective effects on chronic diseases, including $\mathrm{CHD}^{(58)}$. Plants also contain 'secondary metabolites', which increase the plants' overall ability to survive and overcome local challenges ${ }^{(59)}$. Animals (human subjects included) consuming vegetables and fruits may use these networks of phytochemicals for their own purpose, including maintenance of the inflammatory/ anti-inflammatory balance ${ }^{(60)}$ and enhancement of brain 
function $^{(59)}$. Some of these, such as curcumin from the Curcuma longa plant and sulforaphane from cruciferous vegetables (e.g. broccoli), activate nuclear factor erythroid-2 related factor (Nrf2), a key regulating transcription factor of inducible defence systems in the body ${ }^{(61)}$. Nrf2 regulates about 200 genes by binding to their antioxidant response elements $^{(62)}$, causing the coordinated expression of proteins involved in the inhibition of inflammation, detoxification, antioxidant systems, activation of other transcription factors and the metabolism of lipids, $\mathrm{CHO}$, nucleotides and amino acids ${ }^{(63)}$. Insufficient Nrf2 activation has been linked, among others, to $\mathrm{CHD}^{(64,65)}$ and brain degenerative diseases, such as Parkinson's and Alzheimer's disease ${ }^{(66)}$.

\section{Vitamin D}

We found that $98 \%$ of the present study group reported insufficient vitamin D intake, while $95 \%$ did not adhere to the recommendation to take a vitamin $\mathrm{D}$ supplement. As a modulator of inflammatory cells and inflammatory cytokine secretion, low vitamin D status may contribute to chronic inflammatory conditions $^{(67)}$. Several epidemiological studies have linked inadequate vitamin D status to higher susceptibility of immunemediated disorders ${ }^{(68)}$, including $\mathrm{CHD}^{(30)}$. Vitamin D deficiency affects cardiac contractility, vascular tone, cardiac collagen content and cardiac tissue maturation, and has direct effects on vascular smooth muscle cell calcification and proliferation ${ }^{(69)}$. A recent study has shown a high prevalence of vitamin D deficiency in cardiac surgical patients, associated with a twofold higher risk of major adverse cardiac and cerebrovascular events after surgery ${ }^{(70)}$. This raises the question whether vitamin D supplementation before surgery may reduce the risk of adverse events. In line with these data, a meta-analysis of prospective cohort studies has demonstrated an inverse association between circulating 25-hydroxy-vitamin D levels (ranging from 20 to $60 \mathrm{nmol} / \mathrm{l})$ and $\mathrm{CHD}$ risk $^{(71)}$. In addition, there is a growing body of research exploring the association between vitamin D levels and diverse adult neuropsychiatric diseases ${ }^{(72)}$.

\section{Potential effect of diet on coronary artery bypass grafting surgery outcomes}

CABG surgery may be a trigger of an exaggerated inflammatory reaction, resulting in vascular sequels, particularly those leading to neurological dysfunction ${ }^{(4)}$. In this context, correction of nutrient status might be more effective in primary and secondary prevention than in the treatment of an acute event ${ }^{(73)}$. Therefore, the aim should be set in prevention. A healthy food pattern has indeed been identified as a factor that supports health, lowers BMI and could potentially promote better operative outcomes in terms of quality of life for at least patients with the metabolic syndrome and cardiac problems ${ }^{(74)}$. This concept appears, however, to be based on the reduction of certain dietary elements (e.g. saturated fat, added sugars and $\mathrm{Na}$ ), rather than on the benefits of other nutrients that are part of a healthy diet $^{(57)}$. Moreover, modest dietary changes harbour low risk, are relatively inexpensive and are widely available compared with drugs, invasive procedures and devices ${ }^{(75)}$.
The above discussion raises the question whether a rapid correction of nutrient status is possible, before CABG intervention. Some nutrients, such as water-soluble vitamins, may be rapidly corrected; however, others (e.g. fat-soluble nutrients) might be less readily distributed among key organs, such as the brain. As an example, DHA half-life in the human brain amounts to approximately 2.5 years ${ }^{(76)}$, which might be the reason why intervention trials with fish oil in neurological diseases (e.g. Alzheimer's disease) show conflicting results ${ }^{(77,78)}$. In contrast, short-term consumption ( 2 weeks) of a diet high in fruit and vegetables (12 servings/d) induced significantly lower lymphocyte DNA damage and pro-inflammatory cytokine production in overweight women compared with an isoenergetic diet low in fruit and vegetables $(2 \text { servings/d })^{(79)}$. In addition, only $10 \mathrm{~d}^{(80)}$ or 2 week $^{(81)}$ consumption of an isoenergetic Palaeolithic-type diet, comprising lean meat, fruit, vegetables and nuts, and excluding cereal grains, dairy or legumes, has been demonstrated to improve blood pressure and glucose tolerance, decrease insulin secretion, increase insulin sensitivity and improve lipid profiles without ${ }^{(80)}$ or with minimal $^{(81)}$ weight loss in healthy sedentary humans ${ }^{(80)}$ and subjects with at least two characteristics of the metabolic syndrome ${ }^{(81)}$.

\section{Limitations}

The present study has many limitations. The participants derived from a single hospital and present results might, therefore, not be generalisable across The Netherlands. However, the similarity of their diets with their counterparts in the healthy Dutch population does not argue in favour of this notion. On the contrary, the employed drop-out criteria rather suggest that the present study group is within the 'better nourished' share of the target population, and that the present results may even be considered 'overoptimistic'. Food pattern was determined by a self-administered questionnaire based on the memory of the participants. The questionnaires used by the Dutch Health Council and the FFQ used within the present study group may not produce the exact same outcomes. However, both questionnaires were translated into the intakes of certain nutrients and were then validated, enabling both outcomes to be comparable. Nevertheless, FFQ are prone to significant systematic and random errors, which can unfavourably affect their analysis and interpretation ${ }^{(82)}$. One of the most common biases is the under-reporting of daily energy intake ${ }^{(19,27)}$ and unhealthy food intake ${ }^{(82)}$ by people with high BMI. We did not collect data on intake of salt, or other CHD-associated lifestyle factors, such as lack of physical activity, insufficient sleep, chronic stress and smoking ${ }^{(83)}$. We also did not investigate vitamin $\mathrm{B}_{12}$. Vitamin $\mathrm{B}_{12}$ deficiency is a common cause of neuropsychiatric symptoms in the elderly population ${ }^{(84)}$. These factors are interrelated and may, therefore, either ameliorate or aggravate the presently encountered poor diet.

\section{Conclusions}

We conclude that the present study population presents poor dietary habits that may theoretically put them at risk of 
a pro-inflammatory state that may worsen their disease and unfavourably affect surgery outcomes. There is an urgent need for intervention trials and education policies aiming at rapid improvement of their unbalanced pre-operative diets to reduce the risk of post-operative death or complications, such as atrial fibrillation and cognitive decline. Dependent on body weight, these interventions should, in our minds, aim at isoenergetic or hypoenergetic diets, with moderate CHO (e.g. $40 \mathrm{E} \%$ ), moderate-high protein (e.g. $25 \mathrm{E} \%$ ), moderate fat $(35 \mathrm{E} \%)$ and supplementation with vitamins $\mathrm{D}$ and $\mathrm{B}_{12}$. This translates into a low-GL, fibre-rich diet that is abundant in micronutrients and phytochemicals from vegetables, fruit and nuts, together with lean meat and (EPA+DHA)-rich fish ${ }^{(85)}$.

\section{Acknowledgements}

The authors thank the cardiothoracic nursing units from the Universal Medical Center Groningen for their help and support in the present study.

The present study received no specific grant from any funding agency and commercial or not-for-profit sectors.

The authors' contributions are as follows: B. R.-N., M. A. M., M. J. L. D., D. A. J. D.-B. and F. A. J. M. designed the study; B. R.-N. and G. H. A. M. v. d. H. conducted the study; B. R.-N., G. H. A. M. v. d. H. and J. H. M. d. V. analysed the data; B. R.-N. and F. A. J. M. wrote the paper; F. A. J. M. had primary responsibility for the final content of the manuscript. All authors read and approved the final manuscript.

There are no conflicts of interest.

\section{References}

1. Libby P (2012) Inflammation in atherosclerosis. Arterioscler Thromb Vasc Biol 32, 2045-2051.

2. Black HR (1992) Cardiovascular risk factors. In The Yale University School of Medicine Heart Book, pp. 23-35. New York, NY: Hearst Books.

3. Serruys PW, Morice M, Kappetein AP, et al. (2009) Percutaneous coronary intervention versus coronary-artery bypass grafting for severe coronary artery disease. N Engl J Med 360, 961-972.

4. Selnes OA, Gottesman RF, Grega MA, et al. (2012) Cognitive and neurologic outcomes after coronary-artery bypass surgery. N Engl J Med 366, 250-257.

5. Evered L, Scott DA, Silbert B, et al. (2011) Postoperative cognitive dysfunction is independent of type of surgery and anesthetic. Anesth Analg 112, 1179-1185.

6. Eisenächer K \& Krug A (2012) Regulation of RLR-mediated innate immune signaling - it is all about keeping the balance. Eur J Cell Biol 91, 36-47.

7. Bone RC, Balk RA, Cerra FB, et al. (1992) Definitions for sepsis and organ failure and guidelines for the use of innovative therapies in sepsis. The ACCP/SCCM Consensus Conference Committee. American College of Chest Physicians/Society of Critical Care Medicine. Chest J 101, 1644-1655.

8. Rogers J (2008) The inflammatory response in Alzheimer's disease. J Periodontol 79, 1535-1543.

9. Bone RC (1996) Sir Isaac Newton, sepsis, SIRS, and CARS. Crit Care Med 24, 1125-1128.

10. Cormack F, Shipolini A, Awad WI, et al. (2012) A metaanalysis of cognitive outcome following coronary artery bypass graft surgery. Neurosci Biobehav Rev 36, 2118-2129.
11. Straub RH (2011) Concepts of evolutionary medicine and energy regulation contribute to the etiology of systemic chronic inflammatory diseases. Brain Behav Immun 25, 1-5.

12. Ruiz-Núñez B, Pruimboom L, Dijck-Brouwer DAJ, et al. (2013) Lifestyle and nutritional imbalances associated with Western diseases: causes and consequences of chronic systemic low grade inflammation in an evolutionary context. J Nutr Biochem 24, 1183-1201.

13. National Institute for Public Health and the Environment, The Netherlands (RIVM) (2006) Our Food, Our Health. Healthy Diet and Safe Food in The Netherlands no. 270555009. Bilthoven: National Institute for Public Health and the Environment.

14. He K, Song Y, Daviglus ML, et al. (2004) Accumulated evidence on fish consumption and coronary heart disease mortality. Circulation 109, 2705-2711.

15. Feunekes GI, Van Staveren WA, De Vries JH, et al. (1993) Relative and biomarker-based validity of a food-frequency questionnaire estimating intake of fats and cholesterol. $\mathrm{Am} \mathrm{J}$ Clin Nutr 58, 489-496.

16. van Rossum C, Fransen HP, Verkaik-Kloosterman J, et al. (2011) Dutch National Food Consumption Survey 2007-2010. Diet of Children and Adults Aged 7 to 69 Years. RIVM Report 350050006. Bilthoven: RIVM.

17. RIVM (2010) NEVO-online Version 2010/2.O. Bilthoven: RIVM. http://nevo-online.rivm.nl/ (accessed February 2014).

18. Streppel MT, de Vries JH, Meijboom S, et al. (2013) Relative validity of the food frequency questionnaire used to assess dietary intake in the Leiden Longevity Study. Nutr J 12, 75.

19. Siebelink E, Geelen A \& de Vries JHM (2011) Self-reported energy intake by FFQ compared with actual energy intake to maintain body weight in 516 adults. Br J Nutr 106, $274-281$.

20. Molag M (2010) Towards Transparent Development of Food Frequency Questionnaires. $\mathrm{PhD}$ Thesis. Wageningen: University of Wageningen.

21. Health Council of The Netherlands (2006) Guidelines for a Healthy Diet 2006. Publication no. 2006/21E. The Hague: Health Council of the Netherlands.

22. Health Council of The Netherlands (2001) Dietary Reference Intakes: Energy, Proteins, Fats and Digestible Carbohydrates. The Hague: Health Council of the Netherlands. (Publication no. 2001/19, ISBN 90-5549-384-8)

23. US Department of Agriculture and US Department of Health and Human Services (2010) Dietary Guidelines for Americans, 2010, 7th ed. Washington, DC: US Government Printing Office.

24. American Heart Association (2010) Fats and Oils: AHA Recommendation. http://www.heart.org/HEARTORG/Getting Healthy/FatsAndOils/Fats101/Fats-and-Oils-AHA-Recommendation_UCM_316375_Article.jsp (accessed May 2014).

25. Kris-Etherton PM, Harris WS, Appel LJ, et al. (2003) Omega-3 fatty acids and cardiovascular disease: new recommendations from the American Heart Association. Arterioscler Thromb Vasc Biol 23, 151-152.

26. Health Council of the Netherlands (2012) Evaluation of the Dietary Reference Values for Vitamin D. The Hague: Health Council of the Netherlands (no. 2012/15).

27. Amirkalali B, Najafi M, Ataie-Jafari A, et al. (2008) Under- and overreporting of energy in a group of candidates for CABG surgery and its association with some anthropometric and sociodemographic factors, Tehran, Iran. Vasc Health Risk Manag 4, 1115-1120.

28. Najafi M \& Sheikhvatan M (2013) Gender differences in coronary artery disease: correlational study on dietary 
pattern and known cardiovascular risk factors. Int Cardiovasc Res J 7, 124-129.

29. Giugliano D, Ceriello A \& Esposito K (2006) The effects of diet on inflammation: emphasis on the metabolic syndrome. J Am Coll Cardiol 48, 677-685.

30. Borges MC, Martini LA \& Rogero MM (2011) Current perspectives on vitamin $\mathrm{D}$, immune system, and chronic diseases. Nutrition 27, 399-404.

31. Serhan CN \& Chiang N (2008) Endogenous pro-resolving and anti-inflammatory lipid mediators: a new pharmacologic genus. Br J Pharmacol 153, Suppl. 1, 200-215.

32. Marchioli R, Barzi F, Bomba E, et al. (2002) Early protection against sudden death by $n-3$ polyunsaturated fatty acids after myocardial infarction: time-course analysis of the results of the Gruppo Italiano per lo Studio della Sopravvivenza nell'Infarto Miocardico (GISSI)-Prevenzione. Circulation 105, 1897-1903.

33. Yokoyama M \& Origasa H (2003) Effects of eicosapentaenoic acid on cardiovascular events in Japanese patients with hypercholesterolemia: rationale, design, and baseline characteristics of the Japan EPA Lipid Intervention Study (JELIS). Am Heart J 146, 613-620.

34. Mariani J, Doval HC, Nul D, et al. (2013) n-3 Polyunsaturated fatty acids to prevent atrial fibrillation: updated systematic review and meta-analysis of randomized controlled trials. J Am Heart Assoc 2, e005033.

35. Andreasen J \& Schmidt E (2012) Therapeutic potential of marine $n-3$ fatty acids in CABG patients. Curr Opin Pharmacol 12, 142-146.

36. Kromhout D, Giltay EJ \& Geleijnse JM (2010) n-3 Fatty acids and cardiovascular events after myocardial infarction. $N$ Engl J Med 363, 2015-2026.

37. Sublette ME, Ellis S, Geant A, et al. (2011) Meta-analysis of the effects of eicosapentaenoic acid (EPA) in clinical trials in depression. J Clin Psychiatry 72, 1577-1584.

38. Raison CL, Capuron L \& Miller AH (2006) Cytokines sing the blues: inflammation and the pathogenesis of depression. Trends Immunol 27, 24-31.

39. Dinan TG, Stanton C \& Cryan JF (2013) Psychobiotics: a novel class of psychotropic. Biol Psychiatry 74, 720-726.

40. DeMar JC Jr, Ma K, Bell JM, et al. (2006) One generation of $n-3$ polyunsaturated fatty acid deprivation increases depression and aggression test scores in rats. J Lipid Res 47, 172-180

41. Chowdhury R, Warnakula S, Kunutsor S, et al. (2014) Association of dietary, circulating, and supplement fatty acids with coronary risk. A systematic review and metaanalysis. Ann Intern Med 160, 398-406.

42. Ramsden C, Zamora D, Leelarthaepin B, et al. (2013) Use of dietary linoleic acid for secondary prevention of coronary heart disease and death: evaluation of recovered data from the Sydney Diet Heart Study and updated meta-analysis. BMJ 346, e8707.

43. Oh K, Hu F, Manson J, et al. (2005) Dietary fat intake and risk of coronary heart disease in women: 20 years of follow-up of the nurses' health study. Am J Epidemiol 161, 672-679.

44. German JB, Gibson R, Krauss R, et al. (2009) A reappraisal of the impact of dairy foods and milk fat on cardiovascular disease risk. Eur J Nutr 48, 191-203.

45. Micha R, Wallace S \& Mozaffarian D (2010) Red and processed meat consumption and risk of incident coronary heart disease, stroke, and diabetes mellitus: a systematic review and meta-analysis. Circulation 121, 2271-2283.

46. Ruiz-Núñez B, Kuipers R, Luxwolda M, et al. (2014) Saturated fatty acid (SFA)-status and SFA-intake exhibit different relations with serum total cholesterol and lipoprotein-cholesterol: a mechanistic explanation centered around lifestyle-induced low grade inflammation. J Nutr Biochem 25, 304-312.

47. Donnelly KL, Smith CI, Schwarzenberg SJ, et al. (2005) Sources of fatty acids stored in liver and secreted via lipoproteins in patients with nonalcoholic fatty liver disease. I Clin Invest 115, 1343-1351.

48. Schwarz J, Linfoot P, Dare D, et al. (2003) Hepatic de novo lipogenesis in normoinsulinemic and hyperinsulinemic subjects consuming high-fat, low-carbohydrate and low-fat, high-carbohydrate isoenergetic diets. Am J Clin Nutr 77, 43-50.

49. Reaven G (2012) Insulin resistance and coronary heart disease in nondiabetic individuals. Arterioscler Thromb Vasc Biol 32, 1754-1759.

50. De Filippo C, Cavalieri D, Di Paola M, et al. (2010) Impact of diet in shaping gut microbiota revealed by a comparative study in children from Europe and rural Africa. Proc Natl Acad Sci U S A 107, 14691-14696.

51. Maslowski KM, Vieira AT, Ng A, et al. (2009) Regulation of inflammatory responses by gut microbiota and chemoattractant receptor GPR43. Nature 461, 1282-1286.

52. Macia L, Thorburn A, Binge L, et al. (2012) Microbial influences on epithelial integrity and immune function as a basis for inflammatory diseases. Immunol Rev 245, 164-176.

53. Buyken AE, Goletzke J, Joslowski G, et al. (2014) Association between carbohydrate quality and inflammatory markers: systematic review of observational and interventional studies. Am J Clin Nutr 99, 813-833.

54. Boeing H, Bechthold A, Bub A, et al. (2012) Critical review: vegetables and fruit in the prevention of chronic diseases. Eur J Nutr 51, 637-663.

55. He FJ, Nowson CA, Lucas M, et al. (2007) Increased consumption of fruit and vegetables is related to a reduced risk of coronary heart disease: meta-analysis of cohort studies. J Hum Hypertens 21, 717-728.

56. Oyebode O, Gordon-Dseagu V, Walker A, et al. (2014) Fruit and vegetable consumption and all-cause, cancer and CVD mortality: analysis of Health Survey for England data. J Epidemiol Community Health 68, 856-862.

57. Drewnowski A \& Fulgoni VL 3rd (2014) Nutrient density: principles and evaluation tools. Am J Clin Nutr 99, 1223S-1228S.

58. Hertog MG, Feskens EJ, Hollman PC, et al. (1993) Dietary antioxidant flavonoids and risk of coronary heart disease: the Zutphen Elderly Study. Lancet 342, 1007-1011.

59. Kennedy DO \& Wightman EL (2011) Herbal extracts and phytochemicals: plant secondary metabolites and the enhancement of human brain function. Adv Nutr 2, 32-50.

60. Wink M (2010) Annual Plant Reviews Volume 39. Functions and Biotechnology of Plants Secondary Metabolites, 2nd ed. Oxford, UK: Blackwell Publishing Ltd.

61. Su Z, Shu L, Khor T, et al. (2013) A perspective on dietary phytochemicals and cancer chemoprevention: oxidative stress, nrf2, and epigenomics. Top Curr Chem 329, 133-162.

62. Itoh K, Chiba T, Takahashi S, et al. (1997) An Nrf2/small Maf heterodimer mediates the induction of phase II detoxifying enzyme genes through antioxidant response elements. Biochem Biophys Res Commun 236, 313-322.

63. Hayes JD \& Dinkova-Kostova AT (2014) The Nrf2 regulatory network provides an interface between redox and intermediary metabolism. Trends Biochem Sci 39, 199-218.

64. Gounder SS, Kannan S, Devadoss D, et al. (2012) Impaired transcriptional activity of $\mathrm{Nrf} 2$ in age-related myocardial oxidative stress is reversible by moderate exercise training. PLOS ONE 7, e45697. 
65. Li J, Ichikawa T, Villacorta L, et al. (2009) Nrf2 protects against maladaptive cardiac responses to hemodynamic stress. Arterioscler Thromb Vasc Biol 29, 1843-1850.

66. Sandberg M, Patil J, D'Angelo B, et al. (2014) NRF2-regulation in brain health and disease: implication of cerebral inflammation. Neuropharmacology 79, 298-306.

67. Nagpal S, Na S \& Rathnachalam R (2005) Noncalcemic actions of vitamin D receptor ligands. Endocr Rev 26, 662-687.

68. Baeke F, Takiishi T, Korf $\mathrm{H}$, et al. (2010) Vitamin D: modulator of the immune system. Curr Opin Pharmacol 10, 482-496.

69. Baz-Hecht M \& Goldfine AB (2010) The impact of vitamin D deficiency on diabetes and cardiovascular risk. Curr Opin Endocrinol Diabetes Obes 17, 113-119.

70. Zittermann A, Kuhn J, Dreier J, et al. (2013) Vitamin D status and the risk of major adverse cardiac and cerebrovascular events in cardiac surgery. Eur Heart J 34, 1358-1364.

71. Wang L, Song Y, Manson JE, et al. (2012) Circulating 25-hydroxy-vitamin D and risk of cardiovascular disease: a meta-analysis of prospective studies. Circ Cardiovasc Oual Outcomes 5, 819-829.

72. Eyles DW, Burne THJ \& McGrath JJ (2013) Vitamin D, effects on brain development, adult brain function and the links between low levels of vitamin $\mathrm{D}$ and neuropsychiatric disease. Front Neuroendocrinol 34, 47-64

73. Hu F \& Willett W (2002) Optimal diets for prevention of coronary heart disease. JAMA 288, 2569-2578.

74. Berg CM, Lappas G, Strandhagen E, et al. (2008) Food patterns and cardiovascular disease risk factors: the Swedish INTERGENE research program. Am J Clin Nutr 88, 289-297.

75. Mozaffarian D (2007) JELIS, fish oil, and cardiac events, Lancet 369, 1062-1063.

76. Umhau JC, Zhou W, Carson RE, et al. (2009) Imaging incorporation of circulating docosahexaenoic acid into the human brain using positron emission tomography. J Lipid Res 50, 1259-1268.

77. Freund Levi Y, Vedin I, Cederholm T, et al. (2013) Transfer of omega-3 fatty acids across the blood-brain barrier after dietary supplementation with a docosahexaenoic acid-rich omega-3 fatty acid preparation in patients with Alzheimer's disease: the OmegAD study. J Intern Med 275, 428-436.
78. Grimm MO, Zimmer VC, Lehmann J, et al. (2013) The impact of cholesterol, DHA, and sphingolipids on Alzheimer's disease. Biomed Res Int, article ID 814390

79. Yeon J, Kim H \& Sung M (2012) Diets rich in fruits and vegetables suppress blood biomarkers of metabolic stress in overweight women. Prev Med 54, S109-S115.

80. Frassetto LA, Schloetter M, Mietus-Synder M, et al. (2009) Metabolic and physiologic improvements from consuming a Paleolithic, hunter-gatherer type diet. Eur J Clin Nutr 63 , 947-955.

81. Boers I, Muskiet FA, Berkelaar E, et al. (2014) Favourable effects of consuming a Palaeolithic-type diet on characteristics of the metabolic syndrome: a randomized controlled pilot-study. Lipids Health Dis 13, 1-13.

82. Kipnis V, Midthune D, Freedman L, et al. (2002) Bias in dietary-report instruments and its implications for nutritional epidemiology. Public Health Nutr 5, 915-923.

83. Mendis S, Puska P \& Norrving B (2011) Global Atlas on Cardiovascular Disease Prevention and Control. World Health Organization in Collaboration with World Heart Federation, World Stroke Organization. Geneva: World Health Organization.

84. Lachner C, Steinle NI \& Regenold WT (2012) The neuropsychiatry of vitamin $\mathrm{B}_{12}$ deficiency in elderly patients. J Neuropsychiatry Clin Neurosci 24, 5-15.

85. Kuipers RS, Luxwolda MF, Dijck-Brouwer DA, et al. (2010) Estimated macronutrient and fatty acid intakes from an East African Paleolithic diet. Br J Nutr 104, 1666-1687.

86. Eckel RH, Jakicic JM, Ard JD, et al. (2013) 2013 AHA/ACC guideline on lifestyle management to reduce cardiovascular risk. A report of the American College of Cardiology/ American Heart Association Task Force on Practice Guidelines. J Am Coll Cardiol 63, 2960-2984.

87. Institute of Medicine (US) Panel on Micronutrients (2005) Dietary Reference Intakes for Energy, Carbohydrate, Fiber, Fat, Fatty Acids, Cholesterol, Protein and Amino Acids. Panel on Macronutrients Panel on the Definition of Dietary Fiber, Subcommittee on Upper Reference Levels of Nutrients, Subcommittee on Interpretation and Uses of Dietary Reference Intakes, and the Standing Committee on the Scientific Evaluation of Dietary Reference Intakes, Food and Nutrition Board. Washington, DC: National Academies Press. 